This item was submitted to Loughborough's Research Repository by the author.

Items in Figshare are protected by copyright, with all rights reserved, unless otherwise indicated.

\title{
Technology implementation strategies for construction organisations
}

PLEASE CITE THE PUBLISHED VERSION

http://dx.doi.org/10.1108/09699981011038097

PUBLISHER

(C) Emerald

VERSION

AM (Accepted Manuscript)

LICENCE

CC BY-NC-ND 4.0

REPOSITORY RECORD

Henderson, James R., and Kirti Ruikar. 2019. "Technology Implementation Strategies for Construction Organisations”. figshare. https://hdl.handle.net/2134/8130. 
This item was submitted to Loughborough's Institutional Repository (https://dspace.lboro.ac.uk/) by the author and is made available under the following Creative Commons Licence conditions.

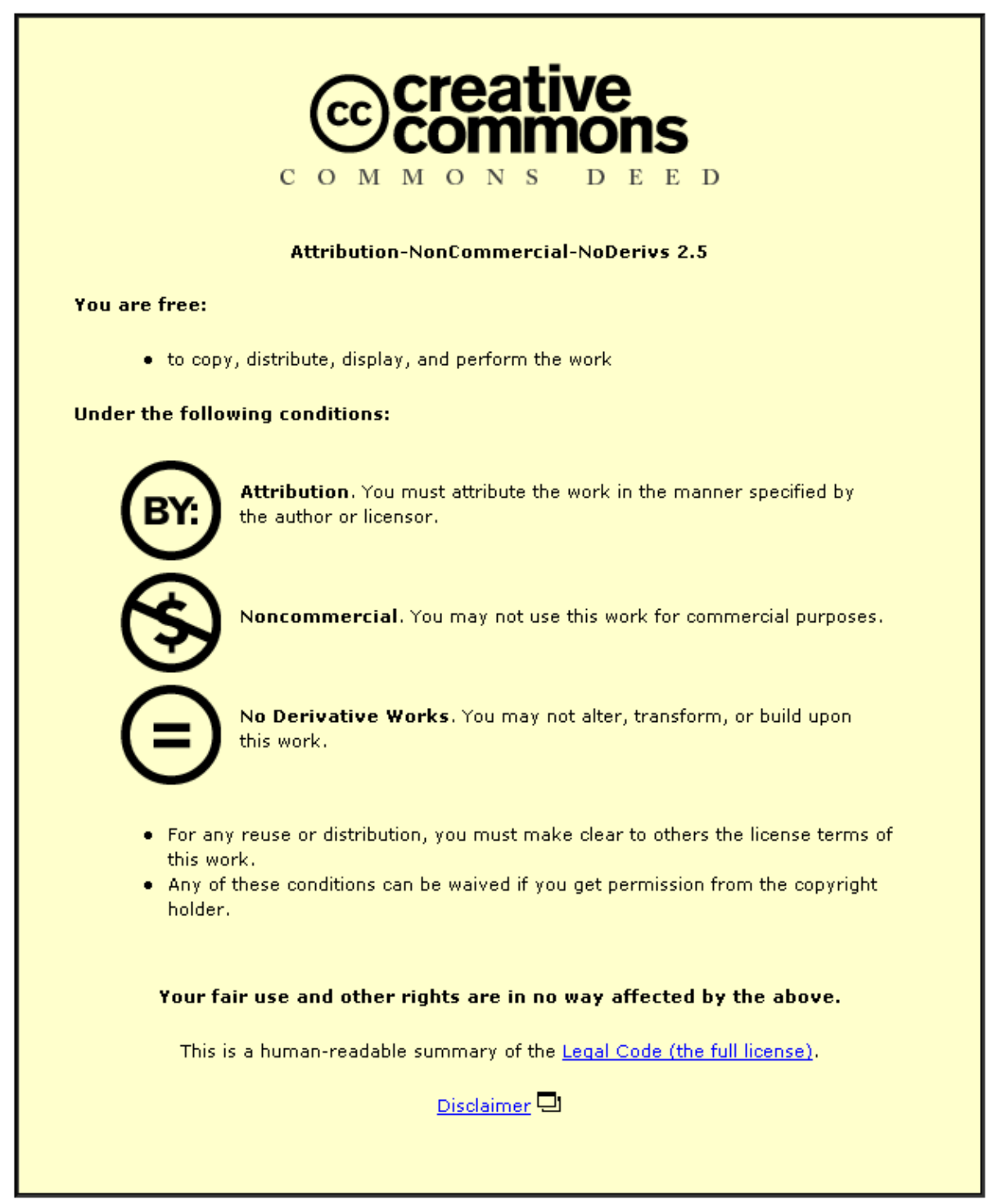

For the full text of this licence, please go to: http://creativecommons.org/licenses/by-nc-nd/2.5/ 


\begin{abstract}
Purpose - This paper presents an overview of the findings of a study aimed at investigating industryspecific factors, which influence the success of technology implementation in construction organisations. These include; the identification of a need, proposal procedures, benefit identification / evaluation, formulation of implementation strategies, implementation barriers, change management and overall implementation evaluation. The findings have been discussed and recommendations to industry for potential improvements have been given.
\end{abstract}

Design/MethodologylApproach - A semi-structured interview-based approach has been adopted to identify the industry-specific factors which influence the success of technology implementation in construction organisations.

Findings - The extent to which successful technology implementation can be achieved, ultimately depends on the degree to which changes are planned, managed and evaluated. Therefore, technology implementation within construction organisations is not so much a technological problem as it is a human behavioural one.

Practical Implications - As technology implementation ultimately consists of changes in practices being made, the fundamental issues regarding technology implementation strategies are well aligned with those of change management. As a result, it is vital that human behavioural and emotional issues are addressed if successful technology implementation is to be achieved.

Originality I Value - An investigation into the industry-specific factors which have resulted in the perception that the construction industry is lagging behind other industries in the uptake of new technologies.

Keywords - Technology, Implementation, Strategy, Construction, Barriers, Change,

Paper Type - Research paper

\title{
INTRODUCTION
}

The construction industry, more so than any other industry, is subject to high degrees of fragmentation (Skibniewski and Nitithamyong, 2004). This lack of unity has been highlighted by many authors as a fundamental obstacle to be overcome in order to achieve the successful implementation of new technologies (Anumba and Ruikar, 2002 and Skibniewski and Nitithamyong, 2004). It is also said to have led to the construction industry lagging behind other industries in the uptake of new technologies (Skibniewski and Nitithamyong, 2004, Marsh and Flanaghan, 2002 and Anumba and Ruikar, 2002).

It is evident that other industries have been able to discover competitive advantage through the absorption of technologies enhancing their processes; however, the extent to which the construction industry is able to do this, or are willing to do this, appears to be significantly reduced. Nevertheless, environmental factors including the ever increasing globalisation of the industry and the fierce economic climate, combined with technological factors such as the progression of technology infrastructures and applications over the past decade, as well as the growing cultural dependence on technology in everyday activates, has called for a need now, more so than ever, to be proactive in the seeking of new initiatives in order to remain competitive.

There has been the tendency in the past to blame the technology itself when desired results have not materialised. This, combined with the difficulty of quantifying the impact of technology within the 
construction industry due to the degree of fragmentation, can be contributed to the slower uptake in new technologies than in other industries. There is; however, evidence that the future of construction is one that embraces technological advances and therefore the time has come where a strategic adoption of technology is required in order to extract its full potential.

Accordingly, this study explores the current strategies of construction organisations in an attempt to identify ineffective or underperforming practises, as well as the drivers and barriers to technology implementation. This is in order to develop recommendations to the industry which achieve a move towards the successful strategic implementation of technologies.

\section{METHODOLOGY OUTLINE}

In order for all issues regarding technology implementation to emerge from this research, a macro level investigation was undertaken. In addition, to ensure the identification of the industry-specific factors which influence the success of technology implementation in construction organisations the research adopted a two phase approach, as follows:

- Phase 1: Initial literature review

- Phase 2: Semi-structured interview process

The initial literature review phase enabled a broad range of scientific literature to be assessed in order to gain a full understanding of previously discovered issues. These included; benefits and drivers of information technology (IT), reasons that affect the uptake of information technologies in construction organisations, how IT investments are evaluated, barriers to implementation, resistance to change/s, and current implementation and evaluation frameworks.

In addition, it also formed the basis for the second phase of research, when semi structured interviews with industry practitioners were conducted. The semi-structured interviews focused on investigating and ascertaining the key issues identified during the initial review stage. Topics covered in the interview questionnaire reflect this. Broadly, the questionnaire covered aspects of: the decision making process, implementation process, how and by whom the need for a new initiative is identified and then proposed, how benefits of new IT initiatives are identified and evaluated, how implementation strategies are formulated, what evident implementation barriers there are, and how change is managed.

A random sample of large construction companies were approached for interviews. These represented a breadth of construction disciplines including construction, building services, engineering, building maintenance, and consultancy organisations. Interview participants were identified on the basis of their positions being either; senior management level and therefore actively involved with the formulation and implementation of strategic management; or, at a level which is directly exposed to the consequences of the implemented strategies. This was recognised as critical as Creswell (1994), states that when selecting participants for sampling, it is essential that all participants experience the phenomenon being studied. An overview of the participant's background and their organisation's disciplines are presented in Table 1. 
Table 1: Interviewee backgrounds and organisation disciplines

\begin{tabular}{|c|c|c|c|}
\hline $\begin{array}{l}\text { Interview } \\
\text { Indicator }\end{array}$ & $\begin{array}{l}\text { Number of } \\
\text { Employees }\end{array}$ & $\begin{array}{l}\text { Discipline area of the } \\
\text { Organisation }\end{array}$ & Job Title \\
\hline Interviewee A & $>30000$ & Construction & Project Manager \\
\hline Interviewee B & $>50000$ & $\begin{array}{l}\text { Consultancy, Construction and } \\
\text { Facilities Management }\end{array}$ & Technical Services Manager \\
\hline Interviewee C & $>8000$ & Engineering & IT Business Analyst \\
\hline Interviewee D & $>2000$ & Building and Civil Engineering & Business Systems Manager \\
\hline Interviewee $\mathrm{E}$ & $>2000$ & Regeneration Housing Agency & $\begin{array}{c}\text { Quality and Value } \\
\text { Development Manager }\end{array}$ \\
\hline Interviewee F & $>4000$ & $\begin{array}{l}\text { Building Services and Building } \\
\text { Maintenance }\end{array}$ & Project Engineer \\
\hline Interviewee G & $>11000$ & Construction and Civil Engineering & $\begin{array}{c}\text { Strategic Development and } \\
\text { Business Improvement } \\
\text { Manager }\end{array}$ \\
\hline Interviewee $\mathrm{H}$ & $>2000$ & Construction & $\begin{array}{c}\text { Project Delivery and } \\
\text { Business Improvement } \\
\text { Manager }\end{array}$ \\
\hline Interviewee J & $>2000$ & $\begin{array}{l}\text { Project and Cost Management } \\
\text { Consultancy }\end{array}$ & Regional Director \\
\hline
\end{tabular}

All interviewees were sent a predefined interview questionnaire prior to the interview so that they were able to fully understand the questions, as well as prepare answers. Face-to-face interviews were conducted where possible in order to establish a stronger rapport with the interviewee, as well as to benefit from being able to assess additional, non-verbal communication such as body language (Hakin, 1997). Telephone interviews were conducted, when the location of the interviewer and interviewee, as well as their individual time demands were uncomplimentary. All interviewees were encouraged to divulge their experiences and real life examples, whilst the semi-structured interview format facilitated additional probing to extract further information where necessary. Analysis of the data was mainly carried out qualitatively; however, for illustrative purposes, quantitative representations supplemented the findings where appropriate. The next section presents the main findings from the interviews.

\section{MAIN RESEARCH FINDINGS}

\section{Decision Making Process}

It was observed that varying forms of decision-making methods were adopted within the interview sample (see Figure 1).

\section{"Take in Figure 1"}

It was regarded by the interview sample that differing decision-making variables, for example, the size of the investment involved, or the array of interest areas and/or employees to be affected; may determine the suitability of the decision maker, (senior management, lower levels, or a combination of levels). For example, Interviewee D stated that; 
"It is different depending on the size of the budget or the degree of risk of the project. If it is a very large project it will go to the top of the organisation for their approval. However, if it is not a very large project then it will stay at the level of the budget holders' responsibility".

This being said, it has been highlighted throughout this study that transparency of the entire decisionmaking process is vital in order to overcome many apparent barriers to implementation, with the need for this to stem to as many areas of the organisation as reasonably possible.

Through the incorporation of more extensive multiple-level involvement as well as improved two-way communication mediums in all stages of the implementation process, benefits including the reduction of barriers such as resistance to change can be experienced. This is due to the reduction in the levels of uncertainty surrounding any impending changes that is experienced by employees due to their increased involvement and therefore awareness.

In addition, Interviewee $\mathrm{J}$ suggested that the decisions were not made at the level to be affected within their organisation as, "this can cause compatibility issues to the rest of their organisation". Similarly, Interviewee $G$ dismisses the use of top down decision-making methods because, "if decisions are imposed on people they will get rejected".

The implications of these findings is a need to move away from the decision-making procedures of; decisions being made by senior management and then imposed onto the organisation (top-down), or that of decisions being made at the level that will ultimately be affected. Alternatively, a move towards the adoption of decisions being made by conducting discussions between the various hierarchical levels should be sought.

Although this process may reduce some of the short-term benefits experienced, such as the speed at which decisions can be made, it was shown to result in far greater long-term benefits. These include; ensuring the long-standing compatibility between decisions, enhancing the degree that the decision has been well informed (through gaining the perspectives of participants from multiple levels of the hierarchy), and most importantly; improving the levels of understanding into decision-making rationale, and the levels of involvement or representation each employee has in the overall process. These latter two benefits heighten the likelihood for successful implementation to be experienced through the reduction in prominence of the most significant barrier to implementation; 'resistance to change'. Barriers to implementation are covered in more detail later in this paper.

\section{Implementation Process}

The implementation process that organisations go through appears to be both well structured and managed effectively. In line with previous study findings conducted by Löfgren (2006) and Irani (2002); some of these organisations hinted that in the past this had not always been the case; however, it has significantly improved over recent years. For example Interviewee $\mathrm{H}$ realises that their organisation "historically has tended to be a 'bolt-on' company where if something was wanted to be achieved, it we would simply be added onto what was already there, even if this resulted in not having the best solution. However, IT is now thought about strategically."

Figure 2 has been generated to illustrate how this widely adopted implementation process consists of an upward progression through the organisational hierarchy. Through initially evolving as the identification of a need, (which was found to usually be provoked by low or middle levels of the hierarchy), middle level management then discuss, outline and mutually agree this need with the initiator(s). Once an agreement of the need is found, the middle level is solely responsible for conducting research into the benefits and potential impacts of any identified solution(s). This identified solution, combined with the researched benefits and drawbacks, therefore forms the basis of a formal proposal, which will ultimately be assessed by senior board members. In some instances, at this stage in the process, the potential implementation method is discussed and included as part of this 
proposal; however this was not evident in all cases. This then leads to costs being assigned to the project and implementation approval sought from senior management.

\section{"Take in Figure 2"}

Interview findings indicate that at this senior most level, a decision into the business attractiveness of the proposal is made. If approval is granted, the process reverts back down the hierarchy, with middle level managers generally empowered to develop a full implementation strategy. The method in which the roll out was generally conducted was phased and on a localised basis initially, involving both middle and low levels of the organisation.

It has reached the point that although gradual improvements can still be made, such as the formulation of the most appropriate implementation strategy for each new initiative, rather than simply utilising one which was seen to be satisfactory in the past; the implementation of new technologies appears to be managed effectively. This being said, this finding may not be a representation of the entire industry's experience, as the interview sample consisted solely of large construction organisations. Therefore it maybe found that for smaller construction organisations, which might have reduced levels of strategic experience and/or managerial expertise, the assessment of this process would generate a less positive conclusion.

An area in which it was recognised that improvements could be made, (similarly to that of the decision-making process), was the level of involvement and contribution that differing levels of the organisation can have in the process. It was identified that, although the lower levels of the organisation are generally the most populated level, the level most emotionally affected by change, as well as the most resistant level towards change; they were also found to be the least involved (see Figure 2).

It has been highlighted by many authors including; Peansupap and Walker (2005), Anumba and Ruikar (2002), and Stephenson and Blaza (2001) that resistance to change is a significant barrier to implementation. This was acknowledged by various interviewees, whilst also suggesting that it is predominantly the lower levels of their organisations that form resistances to change as they are ultimately the level to be most affected. For example, Interviewee $\mathrm{J}$ expresses that, "the lowest levels (i.e. the shop floor) tend to be the biggest resistors. They see the processes that they have done day in day out for years, as not broken so why fix them". As a result this resistance to change leads to negative effects such as; "reduced morale" (Interviewee B), "the need to implement dual processes for those that do not embrace the change" (Interviewee F) and, "the uptake being much slower, which possibly causes the change to be deemed unsuccessful" (Interviewee G).

This study therefore recognises that there is an evident relationship between low levels of involvement within the implementation process and the generation of resistance to change; thus leading to the heightened likelihood of implementation failure. Therefore, through the suggested measures of improving the levels of involvement, as well as the degree of understanding of why the change is being made (i.e. the decision-making rationale), the extent of uncertainty by these lower levels can be reduced. Ultimately, this should result in the reduction of resistance being experienced.

\section{Need Identification}

In general, the organisations interviewed, positively assessed their levels of being proactive in the seeking and uptake of new technology initiatives (see Figure 3).

\section{"Take in Figure 3"}

In contrast the same sample viewed the industry as a whole as being reluctant and slower in the uptake of new technologies compared to other industries such as manufacturing (see Figure 4). 


\section{"Take in Figure 4"}

The seeming lack of compliance between the opinions of these two subject areas, directs towards a variety of conclusions to be drawn.

One of these is that the majority of large construction organisations are proactive in the seeking and uptake of new technologies, but smaller organisations are less so. If this is the case, due to the vast amount of smaller organisations making up the industry, it may dramatically hinder the industry's ability to keep pace with other industries.

In agreement with this view, Interviewee E expresses that "there is a willingness to try new things, but whether this is mirrored across the whole industry, I am not confident". Interviewee G, however, shows a greater degree of assertion towards agreeing with this view by identifying that the industry is "miles behind" and that it is such, "due to the vast majority of the firms making up the industry being so small. This compared to the automotive industry where there are only a few large players, the fragmentation makes it much more difficult to progress".

A differing deduction to be drawn is that when formulating an opinion towards their organisation's proactive or reactive nature, the interviewees are internally focused on their own industry. This is due to them only benchmarking against other construction organisations. If, in fact, these competitors are not proactive themselves, this could lead to an inaccurately positive determination of their organisation.

It was the opinion of Interviewee B that their organisation is not at the forefront of the market, but is "about a third of the way down within the industry". Interviewee A evaluated their company as "being up there with the field", whilst Interviewee $\mathrm{H}$ stated that they did not feel that their organisation was proactive, as they tend to "toe the line of what is necessary and act when they need to".

All three of these views suggest an industry focused review of their organisation's practises, which in two of the cases has led to a positive conclusion to be drawn. This implies in these cases that no measures for immediate improvement will be sought until they feel they may have lost pace with their immediate competitors. However, if a wider perspective was gained and these organisations analysed not only their own organisation against others within their industry, but also against organisations within other industries, a less positive conclusion may be deduced, thus stimulating a desire to develop in this area. Consequently, the industry's rate of adoption would improve.

The final observation to be made and perhaps the one with the greatest degree of support, is that the organisations that partook in the study are proactive in nature; however, transferring this into high levels of technology uptake is laden with difficulties. As a result it is these difficulties (or barriers) which cause the industry to fall behind in new technology adoption.

This is shown by Interviewee $E$ who ascertains that their organisation is proactive in seeking new technologies, "but there is difficulty in identifying which is the most attractive proposal and/or how best to implement it". Both Interviewees A and B indicated that the current economic recession may result in the exasperation of barriers such as access to resources; whilst Interviewee $G$ suggests that although their organisation has "some very clued up employees that actively seek new initiatives (innovators), it is the early and late majority that have the biggest impact on the adoption of new technologies, due to the increase in the existence of resistance to change apparent within these groups."

It is therefore noticeable that all three scenarios detailed above are apparent within the construction industry and are contributing factors to the difficulty that this industry faces regarding the adoption of 
new technologies. For this reason, these issues will be discussed in more detail throughout this paper in order to attempt to address and reduce their significance.

\section{Proposal Procedure}

An area of the need identification process which emerged as currently influencing the reduced rates of technology uptake is the proposal procedure adopted by the majority of the interviewed organisations. At present, this commonly adopted procedure consists of the proposal evolving from low to middle levels of the organisation and having to make the transition vertically up the hierarchy chain (see Figure 5).

\section{"Take in Figure 5"}

During this transition, the initiative has to overcome significant barriers of; requiring an agreement of the need from a superior, as well as time limitations and resource allocation difficulties at each level of the hierarchy that the initiative has to pass through. If the initiative fails to overcome these barriers, then it may be rejected permanently without ever being evaluated by those responsible for assessing the organisational attractiveness of proposed new investments. For example, when asked whether the passing of proposals up the hierarchy chain could lead to its rejection if a superior did not agree with its need, Interviewee B replied, 'It might do yes, even if it was a really good idea. That is a flaw in the system because I can think of a few project managers that would not be overly receptive, as they are outdated in terms of technology'.

An additional drawback of this system was viewed in the form of creating a cycle of disillusionment. This occurs when those that identify and propose new initiatives feel that their efforts have been wasted and/or their proposal was insufficiently assessed. Consequently this results in the initiator becoming emotionally discouraged to proposing initiatives in the future.

The resolution to the drawbacks of this approach appears to lie in a forum based method, which has been illustrated through the generation of Figure 6 .

\section{"Take in Figure 6"}

Usually electronically based, these forums enable all areas of the organisation to efficiently and simply contribute their inputs, either for the proposal of new ideas or towards those already put forward. The benefits of this solution consist of; the speed at which knowledge of proposals can disseminate throughout the organisational hierarchy, the removal of previous barriers to proposal (in the form of time limitations, resources allocation difficulties and the agreement of the need, of intermediate managers), being able to understand the views of participants at all levels of the organisation much more easily (leading to improved transparency of the process), initiatives being developed and improved by other participants, and the true extent of the need being assessed more accurately.

In order to ensure the success of this method, effective training, education and communication to increase the usability and engagement of the system needs to be made. In addition, appropriate administration of the system so that it does not become cluttered, ineffective and ultimately fall into disuse must be implemented. It was also recognised by Interviewee $\mathrm{H}$ that for any proposal procedure to be successful, the implementation of incentives in the form of a reward and recognition scheme should be introduced. As a result, this measure was recognised as being able to reduce the likelihood of a 'cycle of disillusionment' materialising. 


\section{Benefits Realisation}

Previous studies such as Irani (2002) and Löfgren (2006) suggested that only 'direct', financially based and 'hard' benefits were identified in order to defend technological investments. However, it was evident within this study that the benefit realisation process has progressed significantly over recent years and a distinct move towards recognising the need to conduct a much more stringent benefit appraisal has emerged.

This was shown by all of the interviewees expressing that a broad range of benefits are identified for each technological proposal, including; financial, efficiency, functional, informational, direct, indirect, short-term, long-term, internal and in some instances, inter-organisational, cultural and even potential benefits.

Although a consensus over the need for, and the range of benefits identified, appears to have been reached; the organisations interviewed undertake the process using three differing approaches:

1) Utilising senior management's experience and intuition to gauge the benefits and impacts

2) Conducting research into an initiatives advantages and disadvantages

3) Performing a localised trial to assess its attractiveness.

Each method was recognised to have its own individual benefits and drawbacks (see Table 2), resulting in the belief that the sole use of one method is unsatisfactory. It is therefore proposed that the use of a combination of all three methods would greatly enhance the extraction of usable information and improve the extent to which any decisions made, are 'informed'.

Table 2: Benefits and drawbacks of differing evaluation methods

\begin{tabular}{|c|c|}
\hline \multicolumn{2}{|c|}{ Utilising Experience and Intuition } \\
\hline $\begin{array}{l}\text { Benefits } \\
\text { - Speeds up the decision making process } \\
\text { - Involves those that are most well tuned } \\
\text { to the organisation's needs } \\
\text { - The process can be improved overtime } \\
\text { through lessons learnt by the } \\
\text { participants }\end{array}$ & $\begin{array}{l}\text { Drawbacks } \\
\text { - Top-down culture with decision being imposed } \\
\text { - Only senior management perspectives are } \\
\text { gained } \\
\text { - Opportunities could be missed if the need of a } \\
\text { proposal is not fully understood } \\
\text { - Dissemination of knowledge reduced and/or } \\
\text { extracted from the organisation if members leave }\end{array}$ \\
\hline \multicolumn{2}{|c|}{ Research into the Proposal } \\
\hline $\begin{array}{l}\text { Benefits } \\
\text { - Wider range of perspectives gained due } \\
\text { to multiple levels being involved } \\
\text { - The process can be improved overtime } \\
\text { through lessons learnt by the } \\
\text { participants } \\
\text { - A greater understanding of the context } \\
\text { and viewpoints of all hierarchical levels }\end{array}$ & $\begin{array}{l}\text { Drawbacks } \\
\text { - May become too benefit orientated which leads } \\
\text { to impractically high expectations for a new } \\
\text { technology to be deemed successful } \\
\text { - Dissemination of knowledge maybe reduced } \\
\text { and/or extracted from the organisation if key } \\
\text { members leave the organisation }\end{array}$ \\
\hline \multicolumn{2}{|c|}{ Localised Trialling } \\
\hline $\begin{array}{l}\text { Benefits } \\
\text { - Greater range of benefits and impacts } \\
\text { identified } \\
\text { - Improved clarity of benefits and impacts } \\
\text { - Understand the needs and viewpoints } \\
\text { of those affected by any change }\end{array}$ & $\begin{array}{l}\text { Drawbacks } \\
\text { - Incorporates dual processes, leading to work } \\
\text { overload and/or the trial being negatively } \\
\text { perceived } \\
\text { - Lack of understanding of the contexts and } \\
\text { viewpoints of other levels of the hierarchy }\end{array}$ \\
\hline
\end{tabular}




\section{Benefit Evaluation}

As a result of the moves towards identifying a much greater range of benefits and impacts of new technology initiatives, the need is greater now than perhaps ever, for a more structured evaluation framework. This is echoed by Semich (1994), who argues that previous, financially based evaluations such as 'return on investment' (ROI) virtually ignore all of what most companies aim to achieve with IT and therefore calls for an improved method for measuring the value of apparently unquantifiable benefits.

Although more structured, it is crucial that the framework remains capable of customisation so that each project's individual needs and objectives can be incorporated. It is this customisation and flexibility which will enable the benefit evaluation procedure to assess to what extent the project's objectives and the solution, are aligned. It is therefore proposed that a move towards utilising a balanced scorecard approach is made.

\section{Implementation strategy formulation}

It is clearly evident that a strategic focus towards the implementation of new technologies is being embraced within the sample of organisations interviewed. These positive strides have consequently led to a reduction in the prominence of certain strategic based implementation barriers. For example, it was viewed that both the barriers of 'a lack of IT leadership' and 'a lack of organisational strategic planning' have declined compared to their previous significance rating and ranking of prominence identified in a previous study conducted by Stewart et al. (2004).

The strength of this finding is heightened by the consistent evidence that extensive attempts are being made to align the overall business strategy with that of the IT strategy. This is shown by Interviewee $E$ who states;

"Every attempt is made to align them. In effect, they are the same thing, as the IT strategy supports the business strategy."

This being said, the degree to which this is being successfully achieved varies between the interviewed organisations. For example, Interviewee discloses that;

"The business strategy has to come first, but it does not always define closely enough what is required for the IT strategy."

Similarly, Interviewee $\mathrm{G}$ also experiences difficulties in reaching this alignment by stating;

"The IT budget holders tend not to be connected to the needs of the business and as such IT becomes a hindrance to the business strategy instead of being a powerful tool for the business".

As a result of this research, it should therefore be noted that strategic harmony has been perceived as something to be strived for, even if it may never actually be realised. This is due to clear benefits for doing so being identified by Henderson and Venkatraman (1993). These include; overcoming key implementation difficulties, as well as observing and improving misalignments within the organisation and between the organisation and its environment. Consequently it is critical that continued effort is exerted in order to improve further in this area.

\section{Technology Implementation Barriers}

In order to allow a comparison to be made between the findings of this study to that of previous studies, the mean significance and rank of each barrier as discovered by Stewart et al. (2004) is shown in the original mean and original rank column of each table. The discovered mean significance through this current study is shown in the mean significance column, whilst the difference between the 
two findings' significance scores and their respective ranking are shown in the difference and rank difference columns respectively.

The most noteworthy discovery of this secondary analysis was that of the increase in significance of barriers of; 'fear of change and uncertainty of some participants' at a project level (see Table 3) and the 'resistance to change by staff' at an organisational level (see Table 4).

Table 3: Significance of project level implementation barriers

\begin{tabular}{|l|c|c|c|c|c|}
\hline \multicolumn{1}{|c|}{ Barrier Description } & $\begin{array}{c}\text { Mean } \\
\text { Significance }\end{array}$ & $\begin{array}{c}\text { Original } \\
\text { Mean }\end{array}$ & $\begin{array}{c}\text { Original } \\
\text { Rank }\end{array}$ & Difference & $\begin{array}{c}\text { Rank } \\
\text { Difference }\end{array}$ \\
\hline $\begin{array}{l}\text { Fear of change and uncertainty by } \\
\text { some project participants }\end{array}$ & 3.67 & 2.95 & 6 & 0.72 & $\mathbf{4}$ \\
\hline Limited IT expenditure on projects & 3.56 & 3.48 & 2 & 0.08 & $\rightarrow 0$ \\
\hline $\begin{array}{l}\text { Low Technology literacy of some } \\
\text { project participants }\end{array}$ & 3.44 & 3.43 & 4 & 0.01 & 1 \\
\hline $\begin{array}{l}\text { Tight project timeframes inhibit } \\
\text { training and experimenting with IT }\end{array}$ & 3.44 & 4.00 & 1 & -0.56 & 2 \\
\hline Security and privacy issues & 3.11 & 3.31 & 5 & -0.20 & $\rightarrow 0$ \\
\hline Lack of IT leadership on projects & 2.33 & 3.45 & 3 & -1.12 & $\downarrow 3$ \\
\hline
\end{tabular}

Source: Adapted fromStewart et al.(2004)

After being observed by Stewart et al. (2004), as the least significant barriers to implementation at the project and organisational levels respectively, both barriers have emerged as the most significant barrier of all within their respective levels. This signifies that current measures to reduce these particular barriers are being ineffective in overcoming them. In comparison, other barriers at these levels including; 'low technology literacy of some participants,' 'limited IT expenditure on projects,' and 'the reluctance of management investing in innovation;' have seen a decrease or relatively little change in their significance. It can therefore be deduced that measures developed to overcome these specific factors are being much more effective and well received. As a result of this analysis it is evident that improved change management is vital, if the change resistance experienced is to be reduced and therefore successful technological implementation is to evolve.

Table 4: Significance of organisational level implementation barriers

\begin{tabular}{|l|c|c|c|c|c|}
\hline \multicolumn{1}{|c|}{ Barrier Description } & $\begin{array}{c}\text { Mean } \\
\text { Significance }\end{array}$ & $\begin{array}{c}\text { Origina } \\
\text { Mean }\end{array}$ & $\begin{array}{c}\text { Original } \\
\text { Rank }\end{array}$ & Difference & $\begin{array}{c}\text { Rank } \\
\text { Difference }\end{array}$ \\
\hline Resistance to change by staff & 3.67 & 3.00 & 6 & 0.67 & $\mathbf{4}$ \\
\hline $\begin{array}{l}\text { Limited resources available to small } \\
\text { and medium enterprises }\end{array}$ & 3.33 & 3.96 & 1 & -0.63 & $\downarrow 1$ \\
\hline $\begin{array}{l}\text { Lack of perceived return on } \\
\text { investment }\end{array}$ & 3.00 & 3.77 & 2 & -0.77 & $\downarrow 1$ \\
\hline Conservative business practises & 3.00 & 3.02 & 5 & -0.02 & $\mathbf{4}$ \\
\hline $\begin{array}{l}\text { Lack of organisational strategic } \\
\text { planning }\end{array}$ & 2.89 & 3.26 & 3 & -0.37 & $\downarrow 2$ \\
\hline $\begin{array}{l}\text { Reluctance of management investing } \\
\text { in innovation }\end{array}$ & 2.33 & 3.08 & 4 & -0.75 & $\downarrow 2$ \\
\hline
\end{tabular}


In comparison, the same cannot be stated within the industry level barriers (see Table 5). At this level it is apparent that a greater number of barriers have seen an increase in significance. It should however, be noted that the prominence of financially related barriers such as, 'the high cost associated with IT applications,' 'low profit margins' and 'client organisations being cost driven and/or ill-informed,' can be partially accredited to the recent economic downturn. For example, Interviewee $\mathrm{J}$ expresses that, low profit margins is a much more distinct barrier at present, by stating that, "due to the economic climate, we have significantly reduced profit margins compared to a few years ago (possibly from $7 \%$ profits to $0 \%$ ). Therefore this greatly impacts on the organisation's ability to invest in new technology".

Table 5: Significance of industry level implementation barriers

\begin{tabular}{|l|c|c|c|c|c|}
\hline \multicolumn{1}{|c|}{ Barrier Description } & $\begin{array}{c}\text { Mean } \\
\text { Significance }\end{array}$ & $\begin{array}{c}\text { Original } \\
\text { Mean }\end{array}$ & $\begin{array}{c}\text { Original } \\
\text { Rank }\end{array}$ & Difference & $\begin{array}{c}\text { Rank } \\
\text { Difference }\end{array}$ \\
\hline $\begin{array}{l}\text { High cost associated with IT } \\
\text { applications }\end{array}$ & 3.89 & 3.45 & 3 & 0.44 & $\mathbf{4}$ \\
\hline Fragmented nature of the industry & 3.67 & 3.07 & 6 & 0.60 & $\mathbf{4} 4$ \\
\hline $\begin{array}{l}\text { Cost driven and/or ill-informed } \\
\text { client organisations }\end{array}$ & 3.56 & 3.48 & 1 & 0.08 & $\downarrow 2$ \\
\hline Low profit margins & 3.44 & 3.33 & 4 & 0.11 & $\rightarrow 2$ \\
\hline $\begin{array}{l}\text { Lack of leadership by major client } \\
\text { organisations }\end{array}$ & 3.33 & 2.96 & 7 & 0.37 & $\mathbf{4}$ \\
\hline $\begin{array}{l}\text { Cyclical variations in workload } \\
\text { activity levels }\end{array}$ & 3.33 & 2.71 & 8 & 0.62 & $\downarrow 3$ \\
\hline $\begin{array}{l}\text { Poor interoperability between } \\
\text { different organisation / applications }\end{array}$ & 3.11 & 3.46 & 2 & -0.35 & $\downarrow 4$ \\
\hline $\begin{array}{l}\text { Relatively low level of IT } \\
\text { awareness (exposure to IT) }\end{array}$ & 3.11 & 3.18 & 5 & -0.07 & $\downarrow 1$ \\
\hline
\end{tabular}

Source: Adapted from Stewart et al.(2004)

The barrier of, 'the fragmentation of the industry' has increased in significance, which coincides with the findings and opinions of Anumba and Ruikar (2002) and Skibniewski and Nitithamyong (2004) that the industry's fragmentation directly leads to well documented technology implementation problems.

Another barrier to remain relatively important to overcome with a slight increase in significance is 'the lack of leadership by major client organisations'. It is suggested that through the previously proposed combination of benefit identification methods ('managerial experience and intuition', 'research' and 'localised trialling') the strength of evidence into the need for new initiative adoption can be improved, resulting in better client-understanding of the true need for new initiatives.

\section{Change Management}

Throughout this study the importance of effective change management has surfaced as the most critical element of technology implementation if success is to be experienced.

When interviewees were asked, 'how important is overcoming resistance to change in the successful implementation of technologies', without exception every participant's response was either, 'very important', 'critical,' or, 'paramount'. 
A viewpoint echoed by many participants in this study is that of Interviewee $\mathrm{H}$, who states;

"It is the most important thing. It does not matter how wonderful the technology may be, if people do not want it implemented then it will fail."

It was also discovered that top levels of organisations tend to be early adopters who embrace and actively seek change (Moore, 1998) (see Figure 7). This factor, combined with benefiting from the high levels of involvement throughout the entire process (therefore reducing the levels of uncertainty and resistance to change), enables these participants to pass through the change cycle more swiftly.

\section{"Take in Figure 7"}

In contrast, those at lower levels of organisations were identified as populating the late majority psychographic profile group (see Figure 7), who, as identified by Moore (1998), are seen as being less embracing towards change. This pooled with experiencing lower levels of involvement in the change process (therefore heightening the degree of uncertainty, shock and emotional distress that they encounter), proved to be significant in reducing their rate of progression through the change cycle (see Figure 8).

\section{"Take in Figure 8"}

This study has observed that in order to attempt to overcome resistance to change, measures need to be employed in the form of; involvement, training, communication and education. In particular, it is fundamental that these measures are not only present during and post implementation, but precede any change being instigated. As a result, the level of shock and emotional distress experienced by employees at all levels of the organisation can be reduced; thus improving the alignment of the rate of progression through the change cycle of the differing levels (see Figure 9).

\section{"Take in Figure 9"}

This improved alignment should result in the simplification of the change management function due to the synchronisation of the emotional needs of change participants; no matter what level of the organisation they are positioned. It is also expected that effort into improving these areas should provide benefits in the form of reducing the levels of emotional distress (i.e. self esteem) that is experienced by each participant during the change cycle. This in turn can lead to nurturing a culture of greater change acceptance in the future.

\section{Evaluation of the Implementation Process and Lessons Learnt}

A review of the implementation evaluation procedures being performed indicated that there is a distinct lack of structured appraisal currently being conducted. Reasons for emitting such procedures consisted of; "lessons learnt from IT implementations are so bespoke to that individual project that they would not be useful for differing projects" (Interviewee D), or; "the implementation strategy is covered under the evaluation of the overall project" (Interviewee $H$ ). In general it was therefore observed that the need for conducting such an evaluation was not being realised by all.

This failure to conduct a critical evaluation of new technology implementations was viewed by Lyytinen and Robey (1999), as leading to failings being repeated over time and causing them to become associated as a normal situation. Therefore, it is proposed that the generation of a culture that conducts critical evaluations, both post implementation and at regular intervals throughout the process, can lead to the identification of effective 'lessons learnt', and thus enabling the continuous improvement of the process to be achieved. 


\section{CONCLUSIONS AND DISCUSSIONS}

The underlining theme of this study is that due to technology implementation involving a change in practices being made, the fundamental issues regarding technology implementation strategies are to a large extent, aligned with those of change management. In particular it is evident that these issues are predominantly apparent in the behaviours and emotions of humans, which has been shown through the significance of the implementation barriers of 'fear of uncertainty' and 'the resistance to change'.

In order to improve technology implementation strategies, it was found that progress is needed in addressing these behavioural and emotional concerns. It was also viewed that to have the greatest positive impact on overcoming these issues, a minimisation of the initial uncertainty surrounding change, needs to be made. This is due to its evident link with increasing the levels of emotional distress of change participants.

To accomplish this, two-way communication, education, training and understanding of the rationale bringing about change, should all be improved. This is due to it being observed within this study that these aspects can all be enhanced through focusing on increasing the levels of involvement of all participants in every stage of the process.

In summary, although improvements have been identified within specific stages and/or procedures within the implementation process, the degree to which successful technology implementation is achieved, ultimately depends on the degree to which change can be planned, managed and evaluated effectively. It is therefore not so much a technological problem as it is a human behavioural one.

It is therefore expected, through a multi-dimensional approach requiring the effective leadership of; the process, people and culture, a greater adaptability and acceptance of change can be created. This is due to the reduction of emotional distress throughout the change process. The extent to which this has been achieved should be evident in the degree to which the transition of employees from being 'change intolerant' (the late majority and laggards) towards becoming 'change embracing' (innovators and early majority) is observed. If this can become normality at all levels of an organisation, it is expected that improved levels of adoption can be experienced, thus leading to a reduction in the extent to which the construction industry is perceived to be 'lagging behind' that of other industries.

\section{WAY FORWARD}

In order to provide insights into the way forward for future related research, the following recommendations have been made:

As this research project has observed findings from large construction organisations, future investigations into whether these findings are echoed by the entire industry should be made. Through conducting similar research with samples of differing sized organisations, it will enable an insight into what contrasts or similarities there are, as well as the reasons for these. This should enable an assurance that these recommendations are applicable to the industry as a whole, or that more targeted recommendations can be made to varying segments of the industry depending on how the findings converge.

It is also proposed that further research is conducted into how to better align the differing levels of organisations so that they progress through the change cycle at more similar rates. In relation, an investigation into how to reduce the overall emotional distress caused by change on all participants may identify further means to improve people's acceptance levels of future change. This therefore 
could further reduce the prominence of the most significant technology implementation barriers of; resistance towards, and the fear of change.

\section{RECOMMENDAIONS TO INDUSTRY}

Based on this study's findings, the following recommendations to industry can be made:

- An improvement into the degree of involvement experienced by all hierarchical levels, in every stage of the technology implementation process (from need identification to implementation and evaluation) needs to be made.

- To break-down the evident barriers within the currently adopted proposal systems (such as time and resource limitations, as well as the requirement of an agreement of the need from a superior), there is an opportunity to utilise 'share sites' or 'communities of practice'.

- An exploration of combining 'experience and intuition', 'research' and 'localised trialling' benefit identification methods in order to identify a more realistic expectation of each initiative should be made. This will also enhance the strength of evidence to improve the understanding of clients into the need for the adoption of new technology initiatives.

- A more structured evaluation method of benefits versus the impacts of new initiatives needs to be adopted. This should take the form of a balanced scorecard approach, in replacement for this appraisal being based on 'intuition' and 'gut feelings'.

- Enhanced levels of training, education and two-way communication should be incorporated not only post implementation, but also throughout the process and most critically prior to the change materialising. This is so that the levels of shock and uncertainty (and therefore emotional distress) can be reduced.

- A culture should be sought which actively evaluates implementation strategies and processes, at timely intervals throughout, as well as in totality once the process has concluded. This is in order to identify lessons learnt and continuously improve the process.

\section{REFERENCES}

Anumba, C.J. \& Ruikar, K. (2002). 'Electronic commerce in construction-trends and prospects', Automation in Construction, vol.11, pp. 265- 275

Cresswell, J. (1994). Research Design: Qualitative and Quantitative Approach. Sage

Hakim. C. (1987), Research Design - Strategies and Choices in the Design of Social Research. London: Unwin Hyman Ltd

Henderson, J.C. \& Venkatraman, N. (1993). 'Strategic Alignment: : Leveraging Information Technology for Transforming Organizations', IBM Systems Journal,vol.32, no.1,

Irani, Z. (2002) 'Information systems evaluation: navigating through the problem domain', Information \& Management, vol.40, , pp.11-24

Löfgren, A. (2006). 'ICT Investment Evaluation and Mobile Computing Business Support for Construction Site Operations', Proceedings of Helsinki Mobility Roundtable . Sprouts: Working Papers on Information Systems, Vol. 6, no. 29

Lyytinen, K., \& Robey, D. (1999). Learning failure in information systems development. Information Systems Journal, 9, 85-101. 
Marsh, F. and Flanagan, R. (2002). 'Measuring the costs and benefits of information technology in construction', Engineering Construction and Architectural Management, vol.7, no.4, pp. 423-435

Moore, G.A., 1992, revised 1998. Crossing the Chasm. Capstone Publishing Ltd, Oxford.

Peansupap, V. \& Walker, D.H.T. (2005) 'Factors Enabling Information and Communication Technology Diffusion and Actual Implementation in Construction Organisations', Electronic Journal of Information Technology in Construction, Vol. 10 , pp. 193

Semich, J.W. (1994) 'Here's How to Quantify IT Investment Benefits', Datamation , Vol. 40, No.1, pp. 45

Skibniewski,M.J. \& Nitithamyong, P. (2004). 'Web-based construction project management systems: how to make them successful?' Automation in Construction, vol.13, pp.491-506

Stephenson, P. \& Blaza, S. (2001). 'Implementing Technological Change in Construction Organisations', Proceedings of the IT in Construction in Africa conference, Mpumalunga, South Africa, 30 May - 1 June

Stewart, R. A., Mohamed, S. \& Marosszeky, M. (2004). 'An empirical investigation into the link between information technology implementation barriers and coping strategies in the Australian construction industry', Construction Innovation: information, process, management, Vol. 4, pp. 155171 